\title{
Extended Application of Self-Fabricated Covered Stents for Interventions in Adults with Congenital Heart Disease
}

\author{
Subeer K. Wadia, MD ${ }^{1 *}$, Damien Kenny, MB, MD², Wail Alkashkari, MB, MD³, Thomas Matella, RT(R)(CV)4, \\ Clifford J. Kavinsky, MD, PhD ${ }^{5}$, Ziyad M. Hijazi, MD, MPH, MSCAI ${ }^{6}$ \\ ${ }^{1}$ Ronald Reagan UCLA Medical Center, Internal Medicine, Los Angeles, California, USA \\ 2 Division of Pediatric Cardiology, Our Lady's Children's Hospital, Dublin, Ireland \\ ${ }^{3}$ King Faisal Cardiac Center, Jeddah, Saudi Arabia \\ ${ }^{4}$ Rush University Medical Center, Chicago, Illinois, USA \\ ${ }^{5}$ Rush University Medical Center, Division of Cardiology, Chicago, Illinois, USA \\ ${ }^{6}$ Sidra Medical and Research Center, Doha, Qatar
}

\begin{abstract}
Background: Covered stents are widely used outside of the United States to treat adult patients with congenital heart disease. However, these stents have not been approved by the United States Food and Drug Administration (FDA). We describe our experience with large diameter, self-fabricated covered stents for patients with congenital heart disease.

Methods: We retrospectively examined results of adults with congenital heart disease who received a selfdesigned covered stent at our institution. We detailed our method of fabricating the covered stent and modifications in delivery to minimize traction or trauma against the outer covering of the stent.

Results: We implanted 25 fabricated covered stents in 21 patients. The cohort was divided into three disease groups: coarctation of the aorta [group (a), $n=17$ ], pulmonary artery or right ventricle-to-pulmonary artery conduit stenosis [group (b), $n=3$ ], and right-to-left shunting at site of prior anastomosis [group (c), $n=1$ ]. In group (a), the mean systolic pressure gradient was reduced from $35.5 \mathrm{~mm} \mathrm{Hg}$ to $5.7 \mathrm{~mm} \mathrm{Hg}(p<0.001)$. In group (b), the mean stenotic pressure gradient decreased from 37.7 to $8.7 \mathrm{~mm} \mathrm{Hg}$. The patient in group
\end{abstract}

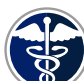

Fax +1 2037853346

E-Mail: jshd@scienceinternational.org

http://structuralheartdisease.org/ (c) 2016 Journal of Structural Heart Disease Published by Science International Corp. ISSN 2326-4004

Accessible online at: http://structuralheartdisease.org/ (c) had obliteration of shunting and improvement in symptoms.

Conclusions: Our self-fabricated covered stents were safe and provided effective gradient reduction or intraluminal continuity to treat individualized lesions related to congenital heart disease. Covered stents increase the therapeutic options for the interventional cardiologist and in some cases may be safer for the patient. There needs to be increased pressure from providers towards the FDA to approve these stents in the United States.

Copyright $\odot 2016$ Science International Corp.

\section{Key Words}

Covered stent - Self-fabricated - Congenital heart disease • Adults

\section{Introduction}

Covered stents are widely being studied as adjunctive or alternative therapeutic options in interventional cardiology [1-4]. Due to the intraluminal continuity afforded by expanded polytetrafluoro-

* Corresponding Author:

Damien Kenny, MB, MD

Rush Center for Congenital \& Structural Heart Disease

Department of Cardiology

1650 W. Harrison St, Chicago, IL 60612, USA

Tel.: +1 312942 6800; Fax: +1 312942 5869; E-Mail: damien_Kenny@rush.edu 
ethylene (ePTFE) covering, there is growing interest for their use in adults with congenital heart disease (ACHD), particularly in high risk older patients with severe or heavily calcified stenotic lesions $[5,6]$. The most recent population based studies from Finland and Norway demonstrated the aging population of complex congenital heart disease resulting from improved early surgical interventions $[7,8]$. As such, we will continue to witness a higher rate of highly individualized late term consequence of palliative surgeries in adults with complex heart disease $[9,10]$. Interventional cardiology in ACHD must mature to provide safe and effective options for this already aging population.

Unfortunately, at present there are no large diameter covered stents approved for use in the United States. However, there are clinical trials ongoing examining the safety of such covered stents. The United States Food and Drug Administration (FDA) has allowed commercially made covered stents, such as the covered Cheatham-Platinum stent (CCPS), to be used on limited basis for emergency or compassionate use in select centers (personal communication, NuMED, Inc.). This handicap not only limits the data on safety and efficacy, but also restricts availability of the stent in standard catheterization laboratories, which are already treating adults with complex heart disease across the country.

In this study, we describe our innovative technique of handcrafting individualized covered stents as an approach to provide a safe and therapeutic option while circumventing the hurdle of commercial availability for transcatheter interventions in ACHD. Specifically, we describe our experience of fabricating covered stents using bare metal stents and EPTFE in the catheterization laboratory with our subsequent immediate and follow up results in a cohort of patients with coarctation of the aorta $(\mathrm{CoA})$, pulmonary artery (PA) or right ventricle-to-pulmonary artery (RV-PA) conduit stenosis, and right-to-left shunt secondary to baffle leak.

\section{Patients and Methods}

Over a 12-year period (from August 2001 to August 2013), we retrospectively identified 21 patients who received a self-designed covered stent for a lesion related to congenital heart disease. We divided the cohort of patients into three subgroups: (a) patients with CoA $(n=17)$, (b) PA or RV-PA conduit stenosis $(n=3)$, and (c) right-to-left shunt secondary to baffle anastomosis leak $(n=1)$. We subsequently performed detailed analysis of the self-fabricated covered stent cohort data, including angiography and follow-up computed tomography $(\mathrm{CT})$.

The median and mean differences in pre- and post-stent gradients for groups (a) and (b) were analyzed using Wilcoxon matched pairs signed ranks test and paired $t$ test analysis, respectively, on Microsoft Excel ${ }^{\circledR}$ (Microsoft, Redmond, Washington). Pulse oximetry and New York Heart Association (NYHA) Classification for Heart Failure were used to assess evolution of symptoms.

\section{Stent Fabrication}

Our method of fabricating the covered stent has been previously described [11]. In short, bare metal stents of appropriate length and diameter were selected. Ten patients had MAX-LD or MEGA-LD stents (ev3, Plymouth, Minnesota), six patients had PG Genesis stents (Cordis Corporation, Warren, New Jersey), and five patients received Palmaz stents (Cordis Corporation, Warren, New Jersey). Covered stents were manufactured in the catheterization laboratory under sterile technique, using ultrathin ePTFE tubing $10 \mathrm{~cm} \times 8 \mathrm{~mm}$ (Zeus, Orangeburg, South Carolina) cut to appropriate length to cover the metal stent exterior (Figures 1 and 2) as previously reported [11].

We altered the method later in our practice by abandoning the suturing technique and instead front-loading the stent prior to application of the covering. The covered stent was then crimped onto the balloon, which had already been threaded through the sheath and tucked back slightly until slightly covered by the sheath. In this latter method of front-loading the stent, we were able to minimize the traction and shear force on the ePTFE covering

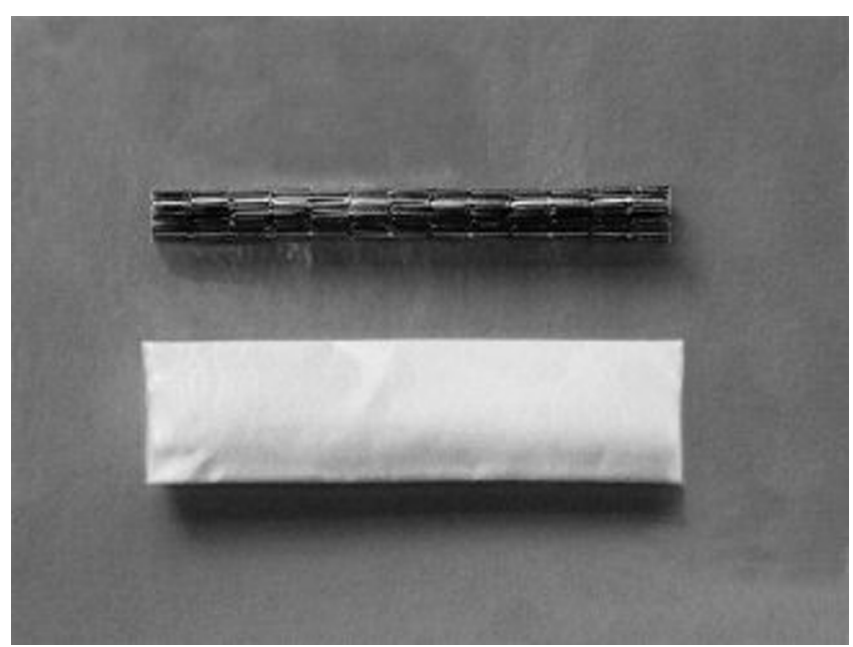

Figure 1. Image demonstrating the bare metal stent and ePTFE cut to an appropriate length to cover the stent. 

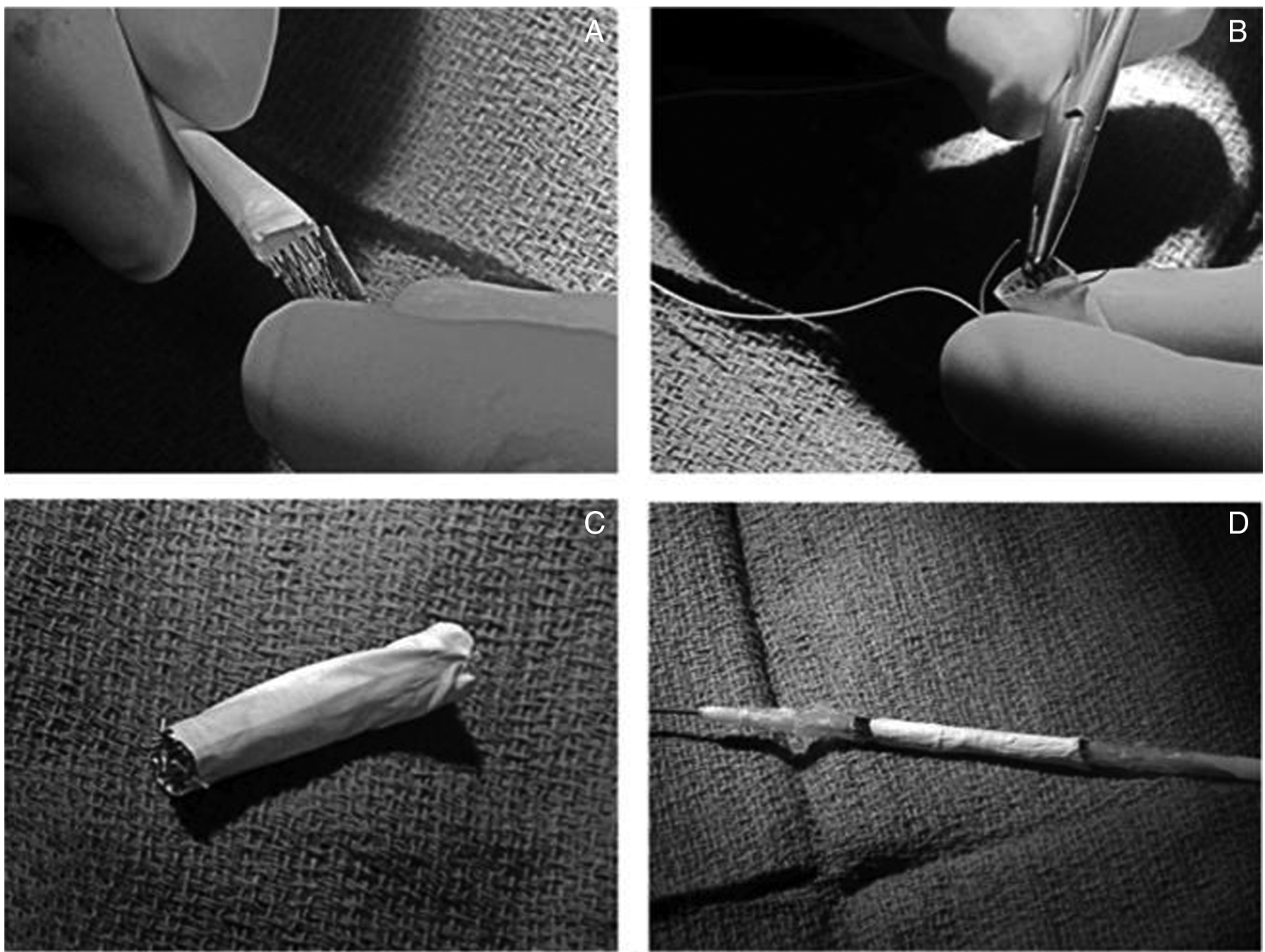

Figure 2. Series of images demonstrating (Panel $A)$ application of the covering over the stent, (Panel $B)$ suturing of the PTFE covering to the stent, (Panel C) the newly self-fabricated covered stent, and (Panel D) following crimping onto the balloon.

during deployment by reducing the distance of stent travel as per the initial method.

\section{Procedure}

All procedures were performed under general anesthesia in a dedicated cardiac catheterization laboratory and guided by biplane fluoroscopy. Patients received an initial bolus of intravenous heparin and antibiotics during the procedure. Femoral vascular approach was used in all cases. In two patients with aortic atresia, simultaneous brachial arterial approach was used to facilitate crossing the stenotic territory from below. Right internal jugular venous access was used in the case of the baffle leak for positioning across the stenotic lesion.

For the coarctation cohort, intravascular ultrasound was used pre- and post-stenting to assess internal dimensions and effects of stenting on vascular wall. Rapid right ventricu- lar pacing was used to reduce the systolic blood pressure by at least $50 \%$ in appropriate cases. Following stent implantation, hemostasis was achieved with the aid of Perclose devices (Abbott Vascular Laboratories, Illinois) in thirteen patients. For the remainder of cases when the artery was felt to be too small, hemostasis was achieved with manual compression. Aspirin was administered to all patients post-procedure and continued at a dose of $5 \mathrm{mg} / \mathrm{kg}$ or maximum $325 \mathrm{mg}$ daily for up to 6 months. Follow up included CT imaging and/or transthoracic echocardiography at 6 months.

\section{Results}

We implanted a total of 25 fabricated covered stents in 21 patients ( 12 male): (a) 17 patients with CoA (mean weight, $70.4 \mathrm{~kg}$ ), (b) 3 patients with PA or RV-PA stenosis (mean weight, $48.3 \mathrm{~kg}$ ), and (c) 
Table 1: CoA Patient Demographics and Procedural Details

\begin{tabular}{|c|c|c|c|c|c|c|c|c|c|}
\hline Pt & Sex & Age (yrs) & Wt (kg) & $\begin{array}{l}\text { Pre-gradient } \\
(\mathrm{mm} \mathrm{Hg})\end{array}$ & Pre-dim (mm) & Stent & $\begin{array}{l}\text { Post-grad } \\
\text { (mm Hg) }\end{array}$ & Post-dim (mm) & Complications \\
\hline 1 & $\mathrm{~F}$ & 24.0 & 61.0 & 33 & 0 & MAX-LD 36 & 3 & 14 & Aneurysm \\
\hline 2 & M & 14.7 & 67.4 & - & - & PG3910 & - & - & None \\
\hline 3 & $\mathrm{~F}$ & 10.2 & 28.0 & 47 & 7 & PG2910 & 17 & 11 & None \\
\hline 4 & $M$ & 42.4 & 80.5 & 40 & 2 & PG2910 & 19 & 10 & None \\
\hline 5 & $F$ & 23.2 & 83.0 & 12 & - & PG3910 & 0 & - & None \\
\hline 6 & $\mathrm{~F}$ & 29.9 & 59.1 & 20 & 5 & MAX-LD 36 & 4 & 11.8 & Fem thrombus \\
\hline 7 & $\mathrm{~F}$ & 29.5 & 88.0 & 69 & 8 & PG3910 & 8 & 14 & None \\
\hline 8 & $M$ & 26.5 & 48.5 & 35 & 0 & PG3910 & 0 & 12 & None \\
\hline 9 & M & 25.4 & 65.5 & 32 & 7.7 & P4010 & 2 & 16 & None \\
\hline 10 & $F$ & 35.5 & 168 & 30 & 6.7 & MAX-LD 36 & 7 & 16 & None \\
\hline 11 & M & 35.0 & 80.5 & 20 & 13 & MAX-LD 36 & 0 & 22 & None \\
\hline 12 & M & 20.0 & 49.7 & 23 & 10 & MAX-LD 36 & 0 & 16 & None \\
\hline 13 & M & 8.9 & 36.2 & 53 & 3 & MAX-LD 26 & 3 & 10 & None \\
\hline 14 & M & 25.4 & 101.2 & 78 & 3.5 & MAX-LD 36 & 17 & 10.5 & None \\
\hline 15 & $\mathrm{~F}$ & 25.8 & 135.4 & 8 & 12.5 & P4010 & 2 & 20 & None \\
\hline 16 & M & 48.6 & 70.3 & 40 & - & MAX-LD 36 & 9 & - & None \\
\hline 17 & M & 34.9 & 97.0 & 28 & 3.2 & P4010 & 0 & 10.6 & None \\
\hline
\end{tabular}

1 patient with a right-to-left shunt from baffle leak (weight $77.9 \mathrm{~kg}$ ). The mean age at stent implantation for each group was 27.1, 24.7, and 25.1 years, with mean follow up 36, 8, and 17 months, respectively.

\section{Group (a): Coarctation of the Aorta}

Among patients with CoA, 12 had native coarctation, 4 had aneurysm formation following a previous intervention, and 1 had re-coarctation following surgery in infancy. Thirteen patients with native or re-coarctation had pre-procedural hypertension. Table 1 lists patient demographics.

The mean systolic pressure gradient fell from $35.5 \mathrm{~mm} \mathrm{Hg}$ to $5.7 \mathrm{~mm} \mathrm{Hg}$ (median change $32.5 \mathrm{~mm}$ $\mathrm{Hg}$ to $3 \mathrm{~mm} \mathrm{Hg} ; p<0.001$ ) following stent implantation (Figure 3). The mean diameter of the CoA increased from $5.83 \mathrm{~mm}$ to $13.9 \mathrm{~mm}$ (median increase $5.85 \mathrm{~mm}$ to $13 \mathrm{~mm} ; p<0.001$ ) post-procedure. There was no residual leak seen on angiography immediately following stent deployment in those patients

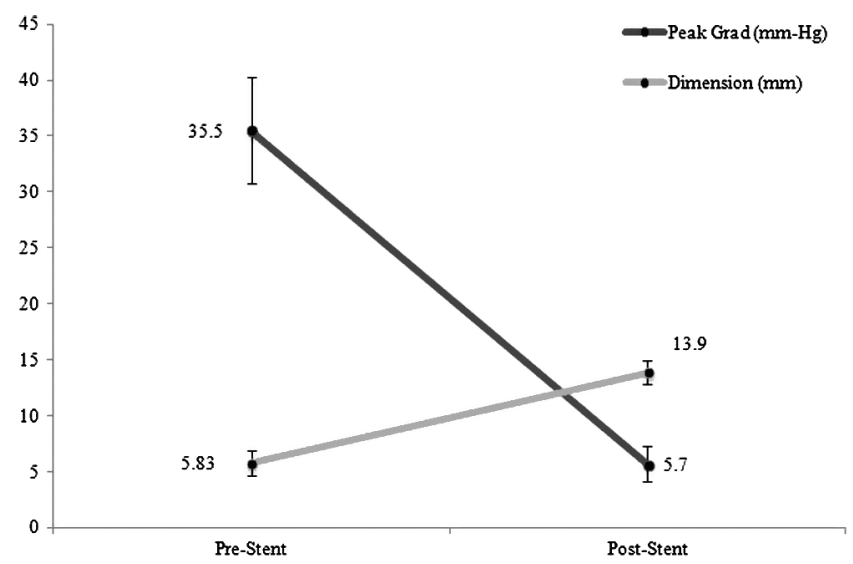

Figure 3. Changes in peak systolic gradient and aortic dimension pre- and post-stent for patients with COA.

with previous aneurysm formation. Median femoral arterial sheath size was 12-Fr (range, 11- to 14-Fr).

One procedure was complicated by femoral artery thrombosis and required femoral thrombectomy. This patient was 30 years old and $59 \mathrm{~kg}$ at the time of the procedure and required a 13-Fr sheath for stent deployment. She recovered completely with no sub- 
sequent complications. Another patient developed aneurysm following stent deployment. This patient was 24 years old with a severe coarctation with a gradient of $33 \mathrm{~mm} \mathrm{Hg}$ across the stenotic lesion. A selfdesigned $36 \mathrm{~mm}$ long MAX-LD (ev3) covered stent mounted on a $16 \mathrm{~mm}$ Z-MED balloon (NuMED) was deployed. Immediately after stent deployment, repeat angiogram revealed the presence of a contained dissection. A 3.4-cm-long, $22 \mathrm{~mm}$-diameter self-expanding stent graft (Medtronic, Minneapolis, Minnesota) was implanted during the procedure with exclusion of flow into the aneurysm. Because of the profile (diameter and length) of the delivery system, a cut down to the left iliac artery was performed to compensate.

Mean follow up was 36 months (range, 1-83 months). Eleven patients had routine follow-up CT scan performed at 6 months post-procedure with no evidence of new aneurysm or flow into residual aneurysm. Four patients underwent planned repeat stent dilatations between six and eight months after implantation. Mean clinic systolic blood pressure was reduced from $149 \mathrm{~mm} \mathrm{Hg}$ to (95\% Cl: 128-161 $\mathrm{mm} \mathrm{Hg}$ ) pre-procedure to $125 \mathrm{~mm} \mathrm{Hg}$ (95\% Cl: 114-135 mm Hg) following procedure $(p<0.001)$.

\section{Group (b): PA or RV-PA Stenosis}

The three patients with PA or RV-PA stenosis presented with dyspnea on exertion. The first patient had left branch PA stenosis with an associated distal left PA aneurysm measuring $13 \mathrm{~mm}$. The second had proximal right PA stenosis. The last patient had a prior Ross procedure with subsequent RV-PA homograft conduit placement. After 7 years, he developed elevated RV pressures (80\% systemic) and systolic dysfunction due to severe conduit obstruction. He underwent pre-stenting of his RV-PA conduit with two selffabricated covered stents followed by transcutaneous pulmonary valve replacement with an Edwards SAPIEN $26 \mathrm{~mm}$ valve (Edwards Lifesciences Corp., Irvine, California). Table 2 lists patient demographics.

The mean systolic pressure gradient across the stenotic lesion fell from $37.7 \mathrm{~mm} \mathrm{Hg}$ to $8.7 \mathrm{~mm} \mathrm{Hg}$ (median change $34 \mathrm{~mm} \mathrm{Hg}$ to $8 \mathrm{~mm} \mathrm{Hg}$ ) following stenting (Figure 4). RV systolic pressure decreased from mean $59.3 \mathrm{~mm} \mathrm{Hg}$ pre-stent (median $59 \mathrm{~mm} \mathrm{Hg}$; range, $38-81 \mathrm{~mm} \mathrm{Hg}$ ) to $34.3 \mathrm{~mm} \mathrm{Hg}$ (median $34 \mathrm{~mm}$ $\mathrm{Hg}$; range, $27-42 \mathrm{~mm} \mathrm{Hg}$ ). All procedures resulted in angiographic improvement with no residual stenosis and no complications.

\section{Group (c): Right-to-Left Shunt from Residual Leak}

The patient in group (c) was a 25 year old man weighing $79.9 \mathrm{~kg}$ who presented with baseline hypoxia (oxygen saturation $85 \%$ ) and exercise-induced shortness of breath. He had a history of L-transposition of the great arteries status post Mustard/Rastelli repair. He presented with a superior baffle leak and right-to-left shunt from superior vena cava to the left atrium at the site of a prior anastomosis.

He underwent placement of an ePTFE-covered P4010 stent over a $20 \mathrm{~mm}$ BIB. After stent deployment and upon further inspection, a linear density on fluoroscopic imaging was seen superior to the stent with persistent narrowing inside the stent. The density was attributed either to soft tissue from a prior procedure (pacemaker lead extraction on the day prior to stenting) or inversion of the ePTFE cover-

Table 2: PA and RV-PA conduit stenosis patient demographics and procedural details.

\begin{tabular}{|c|c|c|c|c|c|c|c|c|c|c|}
\hline Pt & Sex & $\begin{array}{l}\text { Age } \\
\text { (yrs) }\end{array}$ & $\begin{array}{l}\text { Wt } \\
(k g)\end{array}$ & Lesion location & $\begin{array}{l}\text { Pre- } \\
\text { gradient } \\
\text { (mm Hg) }\end{array}$ & $\begin{array}{l}\text { RV pressure } \\
\text { pre-stent } \\
(\mathrm{mm} \mathrm{Hg})\end{array}$ & Stent & $\begin{array}{l}\text { Post- } \\
\text { gradient } \\
\text { (mm Hg) }\end{array}$ & $\begin{array}{l}\text { RV pressure } \\
\text { post-stent } \\
(\mathrm{mm} \mathrm{Hg})\end{array}$ & Complications \\
\hline 1 & F & 8.9 & 22.8 & $\begin{array}{l}\text { Left branch PA } \\
\text { with aneurysm }\end{array}$ & 34 & $59 / 10$ & MEGA LD 36 & 8 & $27 / 8$ & None \\
\hline 2 & $\mathrm{~F}$ & 44.1 & 58.5 & Proximal right PA & 21 & $38 / 12$ & MEGA LD 36 & 0 & $34 / 10$ & None \\
\hline 3 & M & 22.6 & 63.5 & RV-PA conduit & 58 & $81 / 16$ & P4010, P4010 & 18 & $42 / 12$ & None \\
\hline
\end{tabular}

$\mathrm{PA}=$ Pulmonary Artery; RV = Right Ventricle 


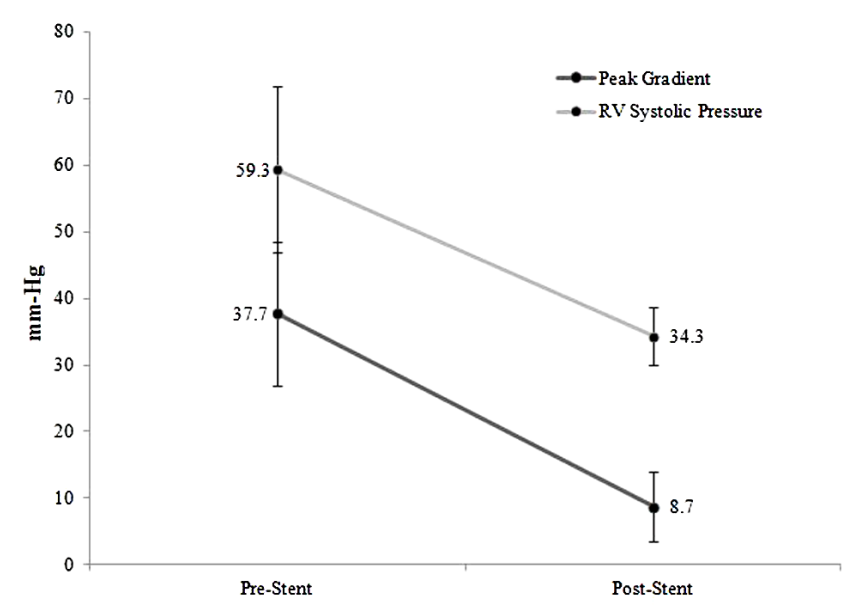

Figure 4. Reductions in peak systolic gradient and RV systolic pressure following stenting of pulmonary artery or right ventricle-to-pulmonary artery conduit stenosis.

ing. A self-expanding Gore Excluder was implanted in the previously placed stent with good stent apposition and no evidence of narrowing or residual leak from the superior aspect of the baffle. At follow up, oxygen saturation on room air had improved from $85 \%$ pre-intervention to $96 \%$ post-stent and he had significant improvement in symptoms.

\section{Discussion}

The complexity of transcatheter interventions in congenital heart disease will need to evolve to keep up with an aging population of CHD who have previously had palliative surgeries. The use of covered stents will expand the options available to adult patients, especially in high-risk cases where surgery may not be a feasible option [12].

In patients with CoA, the risk for late-term aneurysm formation with bare metal stent is 4-7\% [13-15]. In patients with PA stenosis, the restenosis rate with angioplasty alone approaches $15 \%$ with a $4 \%$ risk of aneurysm [16-18]. Perhaps more importantly, current data estimates the risk of conduit rupture or trauma during transcatheter pulmonary valve replacement at $6 \%$ [19]. Late baffle leaks in patients with a history of Mustard or atrial switch is high as well, occurring in up to $25 \%$ of patients with these prior surgeries [20]. The numbers reflect a glaring demand for improved covered percutaneous therapies for adults with CHD.
In this study, we describe our innovative method of designing a covered stent using "on-the-shelf" materials that are already readily available, specifically applying ePTFE to a bare metal stent. The main indication of covered stent in groups (a) and (b) was acute or preexisting aneurysm, or concerns regarding potential for vessel or conduit rupture due to severe stenosis or calcification. Patients deemed higher risk were generally older individuals in circumstances where stenotic thinning and reduced vessel wall compliance predisposed to dissection, rupture, or even death $[3,21]$. The delivery sheath was 2- to 3-Fr larger than the recommended size for the balloon to accommodate the stent, as is consistent with the recommendations for delivery of the CP stent (NuMED, Inc.) [22].

Our preliminary results in the wider spectrum patients warranting stent intervention described here are excellent. In group (a), the median reduction in systolic pressure gradient from $32.5 \mathrm{~mm} \mathrm{Hg}$ to $3 \mathrm{~mm} \mathrm{Hg}$ is comparable to other cohort studies of patients treated with the CP or Advanta $\mathrm{V} 12$ stent $[2,5,6,19,23]$. Only one patient developed contained aortic dissection treated effectively with self-expanding stent graft, highlighting that dissection and extravasation may still occur with balloon-expandable covered stents $[16,17,21]$.

Additionally, group (b) demonstrated significant improvement in both stenotic gradient and RV pressure changes following RVOT stenting. In group (b), one patient had placement of an ePTFE-covered stent as a pre-stent for pulmonary valve replacement, elaborating the potential utility for covered stents in this population. Group (c) was limited to one patient but demonstrated elimination of right-to-left shunt after covered stent, although there may have been inversion of the covering which required a self-expanding Gore Excluder. Our results demonstrate safety and efficacy of our large diameter self-fabricated stent with effective reduction in stenotic gradients, and open the door for expanded application in patients with right-to-left shunts from late baffle leaks.

The covered CP stent was first approved in the United Kingdom in 2004, and the high demand is reflected in large number of stents being shipped from NuMED to European nations (personal communication, NuMED, Inc.). Given that the covered stent has been in widespread use for over a decade in 
Europe, the delay in approval from the FDA is alarming, especially since ACHD are being treated every day across the country but the covered $C P$ stent is only available in highly select centers in the United States under compassionate and emergency use.

Since the publication of our last article first describing our innovative and historic technique of designing covered stents [11], we received numerous inquiries into where we sourced the ePTFE, our methodology, and how we should be utilizing these stents, again echoing the great need for these stents by other providers. Since our publication, Zeus Inc. has unfortunately discontinued availability of the ePTFE covering for this recommendation due to concerns over how it was being used. Nonetheless, our results here demonstrate the technical feasibility of fashioning the covered stent. Although there were initial concerns regarding slippage of the covering created by traction of the stent through the sheath, we have been able to mitigate this issue by front-loading the stent into the sheath after the balloon is threaded first.

We acknowledge that our method of stent production is not an ideal solution, nor should it be overused or abused. Indeed a recent randomized controlled trial comparing bare and covered stent implantation for the treatment of severe native coarctation in adults did not demonstrate any benefit in using a covered stent [24]. However, aortic wall injury will occur and the availability of a covered stent is a necessity to any endovascular intervention where a vessel narrowing is being stretched. Although the covered stent is available for coronary and peripheral interventionalists, the notion that we must create our own covered stents for adults with CHD to provide a safe therapeutic option is an injustice to this population of patients. As a collective group, we are providing a disservice to our patients by not having these stents readily available, especially since they are already in widespread use in other parts of the world. The FDA's allowance of their use in the U.S. under compassionate or emergency use in select centers is in reality a consolation for the underlying failure to ensure that patients have adequate accessibility to what should be considered standard basic and safe care.

Three clinical trials (COAST II, PARCS, and Advanta V12 Atrium covered stent for $(\mathrm{Co}$ ) are already underway looking at the use of covered stents in congenital heart disease. Of these trials, only PARCS is examining the role of covered stents for PA repairs and has already yielded early results on safety and efficacy [19]. Still, the CP and Advanta stents are many years away before being commercially available in standard catheterization laboratories and our need for covered stents to provide proper care is now.

Our need for covered stents will continue to grow. As transcatheter pulmonary valve implantation evolves at a faster rate, there is growing concern over vessel rupture or trauma, especially with the $4-6 \%$ risk of conduit disruption and the risks of expanding homografts already reported [17-19]. These risks are not unreal, and we need a stent to protect against these complications as part of basic care.

Covered stents increase the interventionalist's options for treating high-risk stenoses, aneurysm or baffle leak in adults with CHD. In this study, we show successful reduction in gradients after implantation of self-fabricated covered stents. Additionally, we examine the promising extended application of these stents in adults with branch pulmonary stenoses and baffle leaks with excellent preliminary results and symptom relief. Our study sheds light onto the innovative interventional strategies that can be used to treat the expanding and challenging population of ACHD.

\section{Conflict of Interest}

Ziyad M. Hijazi is a consultant to NuMed, Inc.

Comment on this Article or Ask a Question 


\section{References}

1. Vanagt WY, Cools $B$, Boshoff DE, Frerich $S$, Heying R, Troost E, et al. Use of covered Cheatham-Platinum stents in congenital heart disease. Int J Cardiol. 2014;175:102107. DOI: $10.1016 /$ j.ijcard.2014.04.271

2. Tzifa A, Ewert P, Brzezinska-Rajszys G, Peters B, Zubrzycka M, Rosenthal E, et al. Covered Cheatham-Platinum stents for aortic coarctation: early and intermediate-term results. J Am Coll Cardiol. 2006;47:14571463. DOI: 10.1016/j.jacc.2005.11.061

3. Kenny D, Margey R, Turner MS, Tometzki AJ, Walsh KP, Martin RP. Self-expanding and balloon expandable covered stents in the treatment of aortic coarctation with or without aneurysm formation. Catheter Cardiovasc Interv. 2008;72:65-71. DOI: 10.1002/ccd.21559

4. Cribbs MG, Daniels CJ, Cheatham JP, Zaidi AN. From balloon angioplasty to covered stents in the management of coarctation of the aorta in adults with congenital heart disease. Progr Pediatr Cardiol. 2012;34:97103. DOI: 10.1016/j.ppedcard.2012.08.007

5. Ewert P, Schubert S, Peters B, Abdul-Khaliq $\mathrm{H}$, Nagdyman $\mathrm{N}$, Lange P. The CP stentshort, long, covered-for the treatment of aortic coarctation, stenosis of pulmonary arteries and caval veins, and Fon$\tan$ anastomosis in children and adults: an evaluation of 60 stents in 53 patients. Heart. 2005;81:948-953. DOI: 10.1136/ hrt.2004.040071

6. Butera G, Piazza L, Chessa M, Abella R, Bussadori $C$, Negura $D$, et al. Covered stents in patients with congenital heart defects. Catheter Cardiovasc Interv. 2006;67:466472. DOI: $10.1002 / \mathrm{ccd} .20652$

7. Erikssen G, Liestol K, Seem E, Birkeland $\mathrm{S}$, Saatvedt KJ, Hoel TN, et al. Achievements in congenital heart defect surgery: a prospective, 40-year study of 7038 patients. Circulation. 2015;131:337-346.DOI: 10.1161/CIRCULATIONAHA.114.012033

8. Raissadati $A$, Nieminen $H$, Jokinen $E$, Sairanen $\mathrm{H}$. Progress in late results among pediatric cardiac surgery patients: a population-based 6-decade study with 98\% follow-up. Circulation. 2015;131: 347-353. DOI: 10.1161/CIRCULATIONAHA.114.011190

9. Warnes CA, Liberthson R, Danielson GK, Harris L, Hoffman Jl, Somerville J, et al. Task force 1: the changing profile of congenital heart disease in adult life. J Am Coll Cardiol.
2001;37:1170-1175. DOI: 10.1016/S07351097(01)01272-4

10. Mackie AS, Pilote L, lonescu-Itu R, Rahme E, Marelli AJ. Health care resource utilization in adults with congenital heart disease. Am J Cardiol. 2007;99:839-843. DOI: 10.1016/j. amjcard.2006.10.054

11. Kenny D, Cao Q, Kavinsky C, Hijazi Z. Innovative resource utilization to fashion individualized covered stents in the setting of aortic coarctation. Catheter Cardiovasc Interv. 2011;78:413-418. DOI: 10.1002/ ccd.22999

12. Inglessis I, Landzberg MJ. Interventional catheterization in adult congenital heart disease. Circulation. 2007;115:1622-1633. DOI: 10.1161/CIRCULATIONAHA.105.592428

13. Fawsy ME, Awad M, Hassan W, Al Kadhi Y, Shoukri M, Fadley F. Long-term outcome (up to 15 years) of balloon angioplasty of discrete native coarctation of the aorta in adolescent and adults. J Am Coll Cardiol. 2004;43:1062-1067. DOI: 10.1016/j. jacc.2003.10.040

14. Cowley CG, Orsmond GS, Feola P, McQuillan L, Shaddy RE. Long-term randomized comparison of balloon angioplasty and surgery for native coarctation of the aorta in childhood. Circulation. 2005;111:3453-3456. DOI: 10.1161/CIRCULATIONAHA.104.510198

15. Carr JA. The results of catheter-based therapy compared with surgical repair of adult aortic coarctation. J Am Coll Cardiol. 2006;47:11011107. DOI: 10.1016/j.jacc.2005.10.063

16. Baker CM, McGowan FX Jr, Keane JF, Locke JE. Pulmonary artery trauma due to balloon dilation: recognition, avoidance and management. J Am Coll Cardiol. 2000;36:1684-1690. DOI: 10.1016/S07351097(00)00904-9

17. Peng LF, McElhinney DB, Nugent AW, Powell AJ, Marshall AC, Bacha EA, et al. Endovascular stenting of obstructed right ventricle-to-pulmonary artery conduits: a 15-year experience. Circulation. 2006;113:2598-2605. DOI: 10.1161/CIRCULATIONAHA.105.607127

18. Bush DM, Hoffman TM, Del Rosario J, Eiriksson $\mathrm{H}$, Rome JJ. Frequency of restenosis after balloon pulmonary arterioplasty and its causes. Am J Cardiol. 2000;86:1205-1209. DOI: 10.1016/S0002-9149(00)01203-0
19. Bishnoi RN, Jones TK, Kreutzer J, Ringel RE. NuMED covered cheatham-platinum stent ${ }^{\mathrm{TM}}$ for the treatment or prevention of right ventricular outflow tract conduit disruption during transcatheter pulmonary valve replacement. Catheter Cardiovasc Interv. 2015;85:421-427. DOI: 10.1002/ccd.25682

20. Goff DA, Blume ED, Gauvreau K, Mayer JE, Lock JE, Jenkins KJ. Clinical outcome of fenestrated Fontan patients after closure: the first 10 years. Circulation. 2000;102:2094-2099. DOI: 10.1161/01.CIR.102.17.2094

21. Collins N, Mahadevan V, Horlick E. Aortic rupture following a covered stent for coarctation: delayed recognition. Catheter Cardiovasc Interv. 2006:68:653-655. DOI: 10.1002/ccd.20831

22. Chakrabarti S, Kenny D, Morgan G, Curtis $S L$, Hamilton MC, Wilde P, et al. Balloon expandable stent implantation for native and recurrent coarctation of the aorta-prospective computer tomography assessment of stent integrity, aneurysm formation and stenosis relief. Heart. 2010;96:1212-1216. DOI: 10.1136/hrt.2009.170928

23. Bruckheimer E, Birk E, Santiago R, Dagan T, Esteves C, Pedra CA. Coarctation of the aorta treated with Advanta V12 large diameter stent: acute results. Catheter Cardiovasc Interv. 2010;75:402-406. DOI: $10.1002 / c c d .22280$

24. Sohrabi B, Jamshidi $P$, Yaghoubi A, Habibzadeh A, Hashemi-Aghdam Y, Molin A, et al. Comparison between covered and bare Cheatham-Platinum stents for endovascular treatment of patients with native postductal aortic coarctation: immediate and intermediate-term results. JACC Cardiovasc Interv. 2014;7:416-423. DOI: 10.1016/j. jcin.2013.11.018

Cite this article as: Wadia SK, Kenny D, Alkashkari W, Matella T, Kavinsky CJ, Hijazi ZM. Extended Application of Self-Fabricated Covered Stents for Interventions in Adults with Congenital Heart Disease. Structural Heart Disease. 2016;2(3):79-86. DOI: http://dx.doi. org/10.12945/j.jshd.2016.003.15 